parents of children with severe asthma $(\mathrm{N}=17)$. Discussion guides were initially structured around the revised health belief model (Rosenstock IM, Strecher VJ and Becker MH. Social Learning Theory and the Health Belief Model. Health Educ Behav 1988;15:175-183) which suggests that health behaviours are driven by perceptions in four areas: illness threat, costs and barriers to action, self-efficacy and value of reduced threat. A grounded theory approach was adopted, with concurrent data collection and analysis and adaptations made to the discussion guide in line with emerging themes (Charmaz K. Constructing Grounded Theory. London: Sage, 2006).

Results Many people felt relatively powerless to improve their ongoing health-related quality of life, because the perceived threats to it posed by their asthma were closely matched by perceived threats of treatment side-effects. Coping strategies to improve quality of life were therefore often targeted at social interactions, rather than improving asthma control. The revised health belief model appeared to be relevant to people affected by severe asthma. Conclusions Social support for people with severe asthma may facilitate improved quality of life and interventions that deliver this should be investigated.

\section{P81 THE EFFICACY OF A NURSE LED, PRIMARY CARE, ACUTE ASTHMA SERVICE IN REDUCING SHORT STAY HOSPITAL ADMISSIONS}

doi:10.1136/thoraxjnl-2011-201054c.81

${ }^{1} \mathrm{G} J$ Connett, ${ }^{2} \mathrm{P}$ Lovegrove, ${ }^{2} \mathrm{~S}$ Lovick, ' J P Legg. 'Southampton University Hospitals NHS Trust, Southampton, UK; ${ }^{2}$ NHS Southampton City Trust, Southampton, UK

Current interventions to decrease acute asthma admissions during childhood have achieved limited benefits. We hypothesised that a community asthma nurse service, providing rapid access consultations and an out of hours telephone service, might be an effective strategy in reducing potentially avoidable short stay hospital admissions $(<24 \mathrm{~h})$. We conducted a prospective observational study of the impact of such a service over a 1-year period (2010) using the previous 12 months as a historical control group (2009). There were 176 (64\%) fewer short stay admissions during the intervention period compared with the previous year. The reduction in admissions resulted in gross savings to the NHS of approximately $£ 125000$ based on the national payment by results tariff of $£ 709$ per asthma admission. There were 149 referrals to the asthma nurse service. $53 \%$ were self-referrals. 39 children with poorly controlled asthma were referred by the asthma nurse for hospital assessment. Of these 38 were subsequently admitted for in-patient treatment and 1 was discharged from the emergency department after 4 h. 21 children were judged to be relatively mild and would not have needed hospital admission if referred. 89 cases would either have been referred for hospital assessment or families would have selfreferred to hospital if the service was not available. For this group it was judged by the attending nurse that their interventions had avoided hospital admission. The reduction in short stay admissions was impressive and greater than the number of patient episodes that were addressed by the service. We suspect that this was a knock on effect of good practices being repeated and disseminated within the community without necessarily re-engaging with the service. The number of non-elective short stay asthma admissions has continued to fall in 2011. From January to May 2011 there were just 29 short stay admissions which is $62 \%$ less than the 47 admissions during the same period in 2010. We suggest that this model of care is applicable to many other localities and could result in substantial cost savings to the NHS while providing appropriate care to patients in their homes.

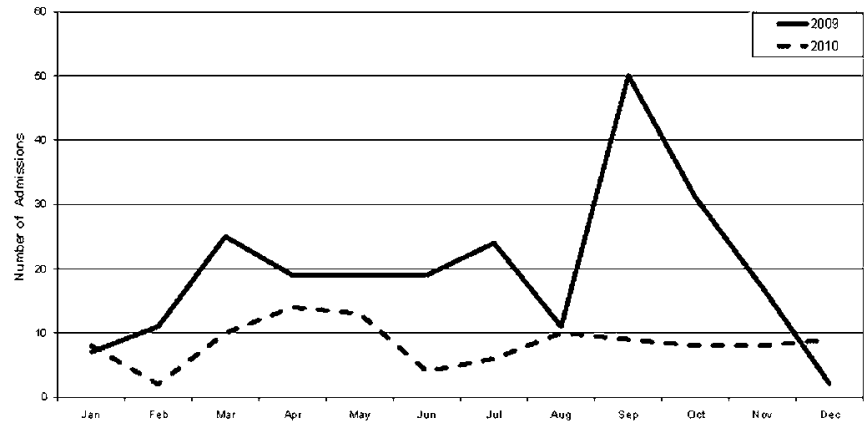

Abstract P81 Figure 1 Number of non-elective asthma admissions with a length of stay $<24 \mathrm{~h}$ by month.

\section{P82 EPISODIC VIRAL WHEEZE AND MULTITRIGGER WHEEZE: ARE THEY REALLY DIFFERENT PHENOTYPES?}

doi:10.1136/thoraxjnl-2011-201054c.82

E Livingstone, G Noble, G Walsh, S Turner. University of Aberdeen, Aberdeen, UK

Introduction Episodic viral wheeze (EVW) and multitrigger wheeze (MTW) are thought to be distinct recurrent wheezing phenotypes in preschool children. Here we tested the hypothesis that there are detectable physiological differences between children with EVW and MTW.

Methods Preschool children with and without a history of recurrent wheeze were recruited, those with symptoms were categorised as EVW or MTW. In a single assessment, the following were completed: questionnaire, respiratory resistance (Rint), bronchodilator response, nasal nitric oxide and skin prick reactivity. Exhaled breath condensate was collected and analysed for interleukin (IL) -10 concentration. A respiratory questionnaire was completed after 12 months. Results There were 69 children recruited, mean age 3.8 years (range 2.1-5.3), of whom 34 had EVW, 19 had MTW and 16 were controls. Skin prick reactivity was determined in 57 , Rint in 55 , bronchodilator response in 43, nasal $\mathrm{NO}$ in 42, exhaled breath condensate in 24 and follow-up was achieved in 53 children. Compared with MTW, children with EVW had increased Rint (mean difference $0.21 \mathrm{kPa} . \mathrm{s} / \mathrm{L}$ [95\% CI 0.06 to 0.36]). Children with MTW were 4.0 times more likely [95\% CI 1.1 to 14.7$]$ to be atopic compared with those with EVW. Compared with controls, children with EVW and MTW had reduced IL-10 concentration in exhaled breath condensate (mean difference $1.35 \mathrm{pg} / \mathrm{ml}$ [95\% CI 1.02 to 1.87$]$. After 12 months, wheeze had apparently resolved in $27 \%(12 / 44)$ children and of the 30 with ongoing wheeze, $27 \%(3 / 11)$ with MTW were categorised as EVW and $52 \%(10 / 19)$ with EVW had developed MTW.

Conclusions There are differences in lung function and atopy between children with EVW and MTW but with considerable overlap in values. The two phenotypes are not necessarily stable over time suggesting they are towards opposite ends of the same spectrum rather than different conditions.

\section{P83 IS A SINGLE INTRAMUSCULAR DOSE OF TRIAMCINOLONE AND ACUTE BRONCHODILATOR SUFFICIENT TO DETERMINE OPTIMAL LUNG FUNCTION IN CHILDREN WITH SEVERE THERAPY RESISTANT ASTHMA?}

doi:10.1136/thoraxjnl-2011-201054c.83

N Cartledge, S Brown, C Bossley, A Gupta, L Fleming, S Saglani, A Bush. Department of Respiratory Paediatrics, Imperial College of Science, Technology and Medicine at the Royal Brompton Hospital and National Heart and Lung Institute, London, UK

Background A small proportion of patients with long standing severe asthma develop irreversible airway obstruction (persistent 